Article

\title{
Superstructure-Based Optimization of Vapor Compression-Absorption Cascade Refrigeration Systems
}

\author{
Sergio F. Mussati ${ }^{1}$, Tatiana Morosuk ${ }^{2} \mathbb{D}$ and Miguel C. Mussati ${ }^{1, * \mathbb{D}}$ \\ 1 INGAR Instituto de Desarrollo y Diseño (CONICET-UTN), Avellaneda 3657, Santa Fe S3002GJC, Argentina; \\ mussati@santafe-conicet.gov.ar \\ 2 Institute for Energy Engineering, Technische Universität Berlin, Marchstr. 18, 10587 Berlin, Germany; \\ tetyana.morozyuk@tu-berlin.de \\ * Correspondence: mmussati@santafe-conicet.gov.ar
}

Received: 30 December 2019; Accepted: 7 April 2020; Published: 10 April 2020

\begin{abstract}
A system that combines a vapor compression refrigeration system (VCRS) with a vapor absorption refrigeration system (VARS) merges the advantages of both processes, resulting in a more cost-effective system. In such a cascade system, the electrical power for VCRS and the heat energy for VARS can be significantly reduced, resulting in a coefficient of performance (COP) value higher than the value of each system operating in standalone mode. A previously developed optimization model of a series flow double-effect $\mathrm{H}_{2} \mathrm{O}-\mathrm{LiBr}$ VARS is extended to a superstructure-based optimization model to embed several possible configurations. This model is coupled to an R134a VCRS model. The problem consists in finding the optimal configuration of the cascade system and the sizes and operating conditions of all system components that minimize the total heat transfer area of the system, while satisfying given design specifications (evaporator temperature and refrigeration capacity of $-17.0^{\circ} \mathrm{C}$ and $50.0 \mathrm{~kW}$, respectively), and using steam at $130{ }^{\circ} \mathrm{C}$, by applying mathematical programming methods. The obtained configuration is different from those reported for combinations of double-effect $\mathrm{H}_{2} \mathrm{O}-\mathrm{LiBr}$ VAR and VCR systems. The obtained optimal configuration is compared to the available data. The obtained total heat transfer area is around $7.3 \%$ smaller than that of the reference case.
\end{abstract}

Keywords: combined refrigeration process; absorption-compression; cascade; R134a (1,1,1,2tetrafluoroetano); water-lithium bromide; double-effect; superstructure; optimization

\section{Introduction}

Refrigeration is one of the varieties of low-temperature thermal engineering applications in different industries such as large food and drink industries, refineries and chemical plants, mechanical engineering, electronic devices, and other types of industries. Currently, the refrigeration industry is playing an important and increasing role in the global economy [1]. Therefore, an intense research and development effort is still required in this area [2,3].

Vapor compression refrigeration systems (VCRS) are the most widely used commercially, followed by the vapor absorption refrigeration systems (VARS). The values of the coefficient of performance (COP) and sizes of the equipment of VCRSs are higher and smaller, respectively, than for VARSs. Additionally, VCRSs can obtain refrigeration temperatures lower than VARSs. The former can be applied for refrigeration temperatures within the operating range between 300 and $120 \mathrm{~K}$ while the latter within the range between 280 and $243 \mathrm{~K}$. The high electrical power consumption for VCRSs is still the main drawback of these systems. Advantageously, not much electrical power is required for VARSs since only a small amount of energy to power a pump is necessary; consequently, they are preferred 
in places where electrical power is expensive or difficult to access. In addition, non-conventional or renewable sources of energy such as geothermal and solar energy, biofuels, and low-grade waste energy can be employed to run VARSs [4]. As there are no moving part inside of components, the maintenance cost of VARSs is relatively low. However, the COP value of VARSs is comparatively low and the investment cost is high, which are the main drawbacks associated with these systems.

Significant research efforts on modeling, simulation, and optimization are currently being put towards overcoming these drawbacks. A literature review reveals that there are many publications addressing the simulation and optimization of double-effect VARSs employing different methodologies: exergy analysis [5-7], exergoeconomic analysis [8,9], evolutionary algorithms [5,10], and rigorous optimization algorithms [11,12]. Arshad et al. [5] optimized the operating conditions to maximize the exergy efficiency of series and parallel flow double-effect $\mathrm{H}_{2} \mathrm{O}-\mathrm{LiBr}$ VARS configurations. The main optimization variables included the operating temperatures at the high and low-temperature generators, evaporator, condenser, and absorber. A pressurized heated water was used as a heating utility in the generators. The authors successfully applied an evolutionary algorithm (genetic algorithm) supported by MATLAB. For a cooling capacity of $300 \mathrm{~kW}$, it was found that the exergy efficiency and COP values obtained for the parallel flow configuration are higher than those obtained for the series configuration. Garousi Farshi et al. [8] applied the exergoeconomic method to analyze in detail three configurations of double-effect $\mathrm{H}_{2} \mathrm{O}-\mathrm{LiBr}$ VARSs for a cooling capacity of $1 \mathrm{~kW}$, arranged in series, parallel, and reverse parallel flow patterns. Pressurized steam was used as a heating utility. The Engineering Equations Solver (EES) software was used to implement the models. For each configuration, the influence of the operating temperature at the high-temperature generator, condenser, absorber, and evaporator on the total investment cost was studied. The evaporator temperature varied from 277 to $283 \mathrm{~K}$. For the three examined configurations, the authors determined that the absorber and evaporator are the most influential process units to the total cost. Mussati el al. [11] optimized the operating conditions and process-unit sizes of a double-effect $\mathrm{H}_{2} \mathrm{O}$ - $\mathrm{LiBr}$ VARS with a series flow configuration for a cooling capacity of $300 \mathrm{~kW}$ and evaporator temperature of $279 \mathrm{~K}$, using saturated steam at $404 \mathrm{~K}$ as a heating utility. To this end, they developed a nonlinear mathematical programming (NLP) model, which was solved with a rigorous optimization algorithm based on the generalized reduced gradient (GRG) method. As a result, a novel configuration was obtained by minimizing the total annual cost investment and operating costs). The obtained configuration differs from the conventional in that in the former the low-temperature solution heat exchanger is removed from the process.

Regarding VCRSs, recent results on modeling and optimization considering single-objective functions can be found in [13-17] and multi-objective functions in [18,19]. By using energy, exergy, and economic analyses, Baakeem et al. [14] theoretically investigated a multi-stage VCRS considering eight refrigerants (R407C, R22, R717, R134a, R1234yf, R1234ze(E), R410A, and R404A). The proposed model was implemented in the EES software and solved using the conjugate directions method. The superheating and subcooling degrees and the operating temperatures at the condenser and evaporator were considered as the optimization variables. For a cooling capacity of $1 \mathrm{~kW}$ and a temperature of $273 \mathrm{~K}$ at the evaporator, the refrigerant R717 showed the highest COP value; the refrigerant R407C was not suggested to use due to the low exergy efficiency and high operating cost. Zendehboudi et al. [18] investigated the performance of VCRSs operating with R450A for cooling capacity values ranging between 0.5 and $2.5 \mathrm{~kW}$. To this end, they developed a multi-objective optimization (MOO) approach coupling the response surface method (RSM) with the non-dominated sorting genetic algorithm II (NSGA-II) method to perform simulation-based optimizations. A case study consisted in minimizing the electrical power required by the compressor and its discharge temperature and maximizing the refrigerant mass flow rate. A second case study consisted in maximizing the cooling capacity and the refrigerant mass flow rate and minimizing the discharge temperature. As in [14], the evaporator and condenser temperatures and the superheating and subcooling degrees were parametrically optimized. The evaporator temperature was varied between 258 and $288 \mathrm{~K}$. A result indicated that the cooling capacity is strongly influenced by the evaporator temperature. 
An integrated system, which combines a VCRS with a VARS, merges the advantages of both standalone systems, resulting in a cost-effective refrigeration system [20,21]. In a combined VCR-VAR system-CVCARS - the electrical power required in VCRS and the heat energy required in VARS can be significantly reduced. This leads to an increase in the COP value $[22,23]$. There are many publications addressing exergy and exergoeconomic analyses of combined VCR-VAR systems that use different mixtures for the absorption cycle (e.g., $\mathrm{H}_{2} \mathrm{O}-\mathrm{LiBr}$ and $\mathrm{NH}_{3}-\mathrm{H}_{2} \mathrm{O}$ ) and different working fluids for the compression cycle (e.g., R22, R134a, R717, and R1234yf) [20,23-31]. Agarwal et al. [20] analyzed an absorption-compression cascade refrigeration system (ACCRS) by combining a series flow triple-effect $\mathrm{H}_{2} \mathrm{O}$-LiBr VARS with a single VCRS operated with R1234yf. High-pressure generator, evaporator, and absorber temperature values ranging between 448.15 and $473.15 \mathrm{~K}, 223.15$ and $263.15 \mathrm{~K}$, and 298.15-313.15 K, respectively, were considered. The authors applied exergy analysis to calculate the performance parameters. They found that the amount of energy recovered in this configuration allowed to drastically reduce the energy input in the high-temperature generator and, consequently, the operating cost. No significant increases in the process-unit sizes were observed. Colorado and Rivera [31] presented a theoretical study to compare, from the point of view of the first and second laws of thermodynamics, the integration of VCRS and VARS considering both single and double-stage configurations for VARS, and using $\mathrm{CO}_{2}$ and R134a for VCRS and $\mathrm{H}_{2} \mathrm{O}-\mathrm{LiBr}$ for VARC. As a result, they found that the highest irreversibilities are in the absorber and evaporator for both mixtures. Additionally, they concluded that, independently of the configuration (single or double-stage arrangements) the total irreversibility obtained for $\mathrm{R} 134 \mathrm{a} / \mathrm{H}_{2} \mathrm{O}-\mathrm{LiBr}$ is significantly lower than that obtained for $\mathrm{CO}_{2} / \mathrm{H}_{2} \mathrm{O}-\mathrm{LiBr}$.

Exergy and exergoeconomic analyses are valuable tools to more accurately identify and quantify the thermodynamic inefficiencies associated with the components and the overall system. However, the application of the exergy analysis in order to obtain the optimal process configuration may require excessive computation time and a large number of iterations when the process under study involves many pieces of equipment. In addition, the designer's interpretation plays an important role in obtaining improved process designs [32]. Several authors have applied genetic algorithms (GAs) to optimize ACCRS [24,33]. By using the NSGA-II technique, Jain et al. [33] solved a MOO problem for a single-effect $\mathrm{H}_{2} \mathrm{O}-\mathrm{LiBr}$ VARS coupled to a VCRS operated with R410A, for a specified cooling capacity of $170 \mathrm{~kW}$. The objective function selected was the minimization of the total irreversibility rate (as a thermodynamic criterion) and the total product cost (as an economic criterion). The authors compared the solutions obtained for the MOO problem with those obtained by considering the individual single-objective functions, concluding that the former are preferred over the latter. GAs, a class of evolutionary algorithms, were successfully applied in optimizing not only refrigeration systems but also complex engineering problems. In GAs, only the values of the objective functions are used without requiring any information about the gradient of the function at the evaluated points. Depending on the cases, GAs can obtain solutions close to the optimal solution in reasonable computation time. However, GAs require many input parameters that can influence the obtained solutions. Recently reported experimental results on CVCARSs can be found in [34,35].

Based on the available information, it can be concluded that different combinations of vapor compression and vapor absorption processes are promising options for combined refrigeration systems; therefore, there is a need to continue investigating and assessing their strengths and weaknesses [36]. The aforementioned studies on CVCARSs employ mainly simulation-based optimization methods for given fixed process configurations. Despite a vast reference on this matter, there are no studies on the simultaneous optimization of the process configuration, process-unit sizes, and operating conditions of CVCARSs running with low-grade waste heat, using mathematical programming techniques and rigorous optimization algorithms. The current work focuses on this aspect.

This paper is a logic continuation of the work recently published by Mussati et al. [11], where an optimization model for the conventional series flow double-effect $\mathrm{H}_{2} \mathrm{O}-\mathrm{LiBr}$ VARS was presented. The model is extended to a superstructure-based model to embed several candidate configurations 
with the aim to include the configuration of the process as an optimization variable. Then, the resulting VARS model is coupled to a model of the conventional VCRS, thus obtaining the desired model of the Vapor Compression-Absorption Cascade Refrigeration System (VCACRS). This model allows systematically determining the optimal configuration of the VCACRS from the proposed superstructure, the process-unit sizes, and the operating conditions simultaneously. The number of degrees of freedom of the resulting optimization model is significantly increased with respect to both standalone processes, thus allowing to find novel and/or improved system configurations.

\section{Process Description}

\subsection{Vapor Absorption Refrigeration System (VARS)}

Figure 1 shows the schematics of a single-effect and a series flow double-effect $\mathrm{H}_{2} \mathrm{O}$ - $\mathrm{LiBr}$ VARS. The double-effect system involves two generators $\mathrm{G}$ (the low-temperature generator LTG and the high-temperature generator HTG), two condensers C (LTC and HTC), and two LiBr solution heat exchangers SHE (LTSHE and HTSHE). Additionally, two solution expansion valves (LTSEV and HTSEV), two refrigerant expansion valves (LTREV and HTREV), a solution pump (PUMP), an absorber (ABS), and an evaporator (EVAP) are involved.

The refrigeration process is taking place in EVAP. The refrigerant leaving EVAP is absorbed by the strong $\mathrm{LiBr}$ solution that enters ABS, producing a weak $\mathrm{LiBr}$ solution stream. The heat of the absorption process is removed by the cooling water. Compared to the energy input required in HTG and LTG, the electrical power required by PUMP to pump the LiBr solution is negligible. In LTSHE and HTSHE, the strong and weak $\mathrm{LiBr}$ solutions exchange heat resulting in a decrease of the heating utility demand in both LTG and HTG. In HTG and LTG, the refrigerant $\left(\mathrm{H}_{2} \mathrm{O}\right)$ is separated from the corresponding weak $\mathrm{LiBr}$ solution obtaining a strong $\mathrm{LiBr}$ solution stream and a vapor stream in each. As the solute $(\mathrm{LiBr})$ determines an increase of the boiling point of the solution with respect to that of the refrigerant $\left(\mathrm{H}_{2} \mathrm{O}\right)$, the separated vapor in both generators is at superheated conditions. Then, the vaporized refrigerant streams generated in HTG and LTG are condensed in HTC and LTC, respectively, using cooling water. The operating pressure in EVAP is achieved by means of LTREV.

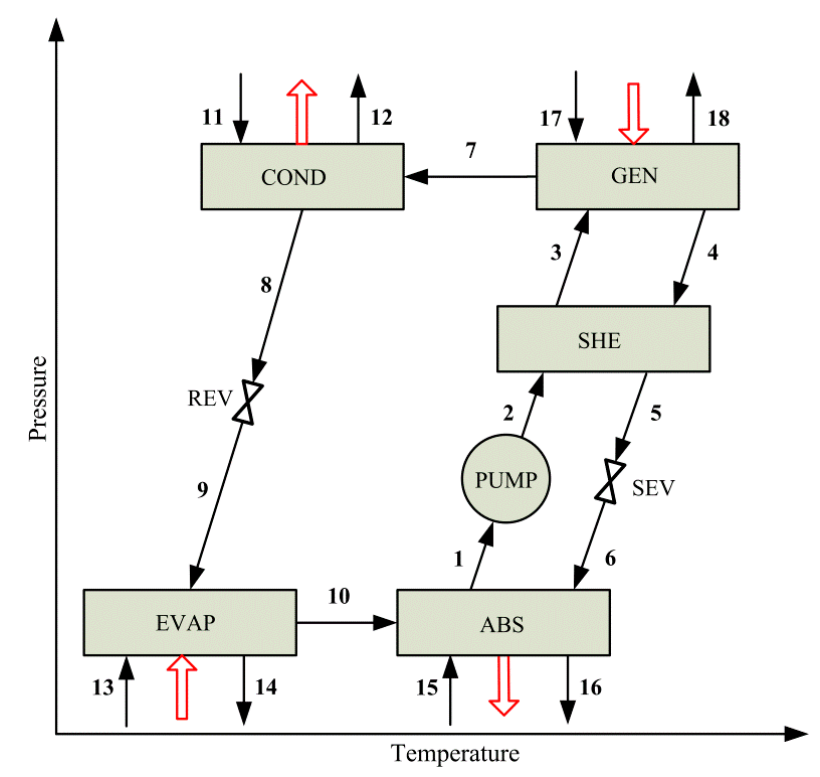

(a)

Figure 1. Cont. 


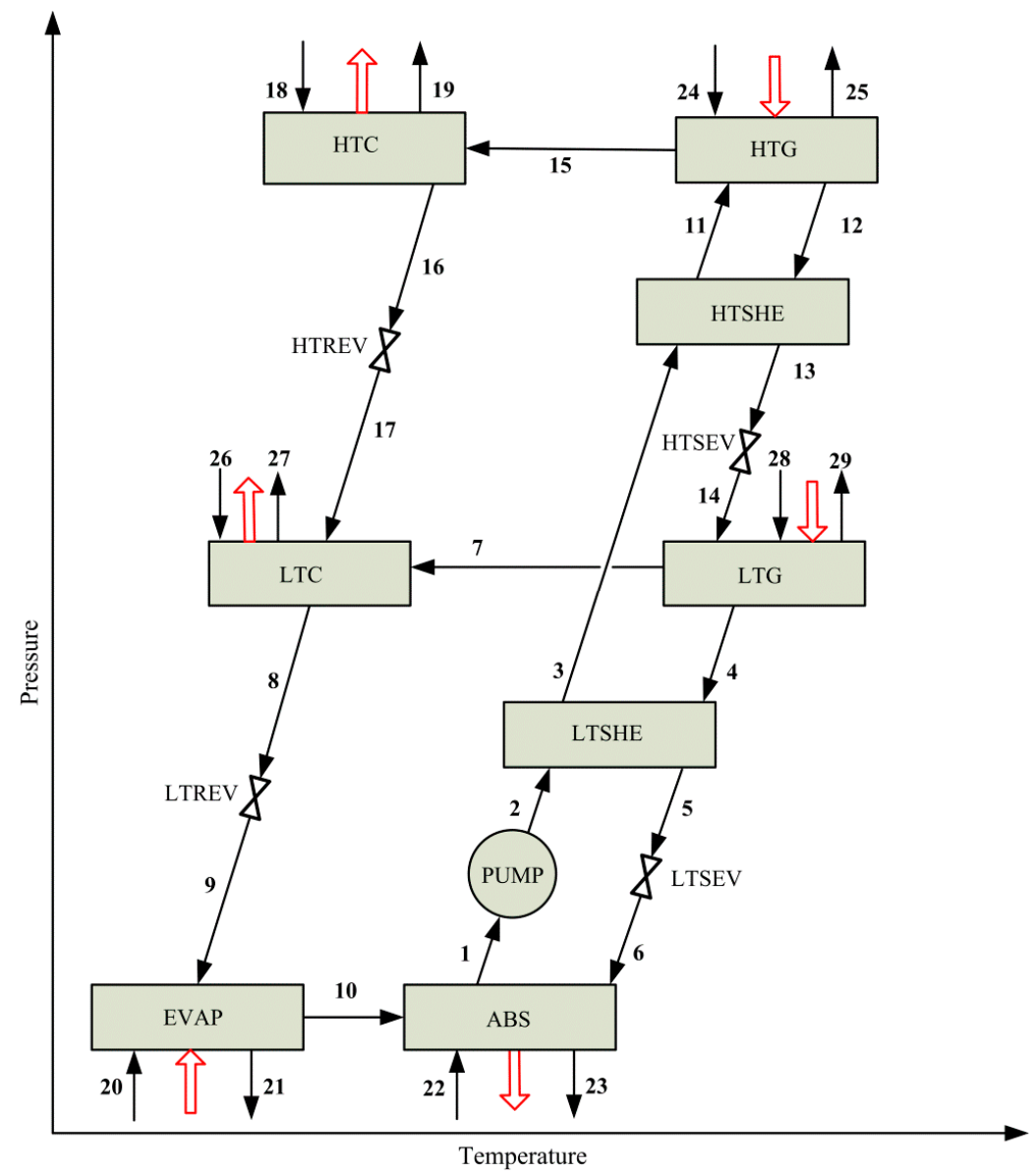

(b)

Figure 1. Schematics of vapor absorption refrigeration systems: (a) single-effect system; (b) series flow double-effect system.

\subsection{Vapor Compression Refrigeration System (VCRS)}

Unlike VARSs, VCRSs operate with electrical power as driving energy. Figure 2 shows a schematic of a simple VCRS. The system consists of an evaporator (EVAP), a compressor (COMP), a condenser (COND), a refrigerant expansion valve (REV), and an economizer (ECON).

By comparing Figures 1a and 2, it can be seen that the compressor in a simple VCRS replaces the absorber, the pump, the solution heat exchanger, the generator, and the expansion valve involved in a conventional single-effect VARS. 


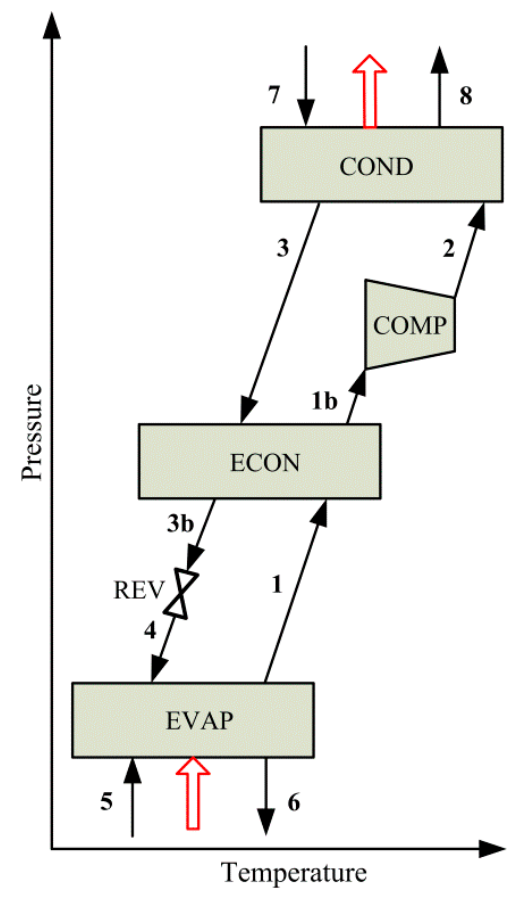

Figure 2. Schematic of a simple vapor compression refrigeration system.

\section{Problem Statement}

As mentioned in the Introduction section, the simultaneous optimization of VCACRSs by applying mathematical programming is addressed. Several possible process configurations are embedded in a single superstructure representation of the studied system (Figure 3), which is a combined process formed by a series flow double-effect $\mathrm{H}_{2} \mathrm{O}-\mathrm{LiBr}$ VARS and a simple VCRS operating with R134a.

The proposed superstructure involves at least 10 alternative configurations, which differ in the way the components HTC, LTC, HTG, LTG, HTSHE, and LTSHE are combined or interconnected, or if some of them (HTC, HTSHE, LTSHE, and ECON) are removed from a given configuration. The components of the compression cycle (EVAP, COMP, COND/EVAP, REV) and ABS, PUMP, LTG, HTG, LTC, LTREV, LTSEV, and HTSEV of the absorption cycle are fixed in the superstructure i.e., they are present in all configurations. For instance, a candidate configuration may include HTC, HTSHE, and LTSHE; other candidate configuration may integrate energetically HTCG with LTG through the splitter SPL with elimination of HTC, but keeping HTSHE and LTSHE; other options may integrate energetically HTG and LTG through SPL with elimination of HTC as well as LTSHE and/or HTSHE from the superstructure, among other alternatives.

The optimization problem can be stated as follows. Given are (a) the superstructure of VCACRS (Figure 3) that embeds a number of combinations of the aforementioned optional and fixed system components, (b) specified values of evaporator temperature and refrigeration capacity of $-17.0^{\circ} \mathrm{C}$ and $50.00 \mathrm{~kW}$, respectively, and (c) steam at $130.0^{\circ} \mathrm{C}$ and cooling water at $25.0^{\circ} \mathrm{C}$ as utilities. The problem consists on finding the optimal VCACRS configuration and the sizes and operating conditions of all system components that minimize the total heat transfer area (THTA) of VCACRS while satisfying the mentioned design specifications.

The obtained optimal solution is compared in detail to a design reported in Colorado and Rivera [31], which is used as a reference design for this paper. 


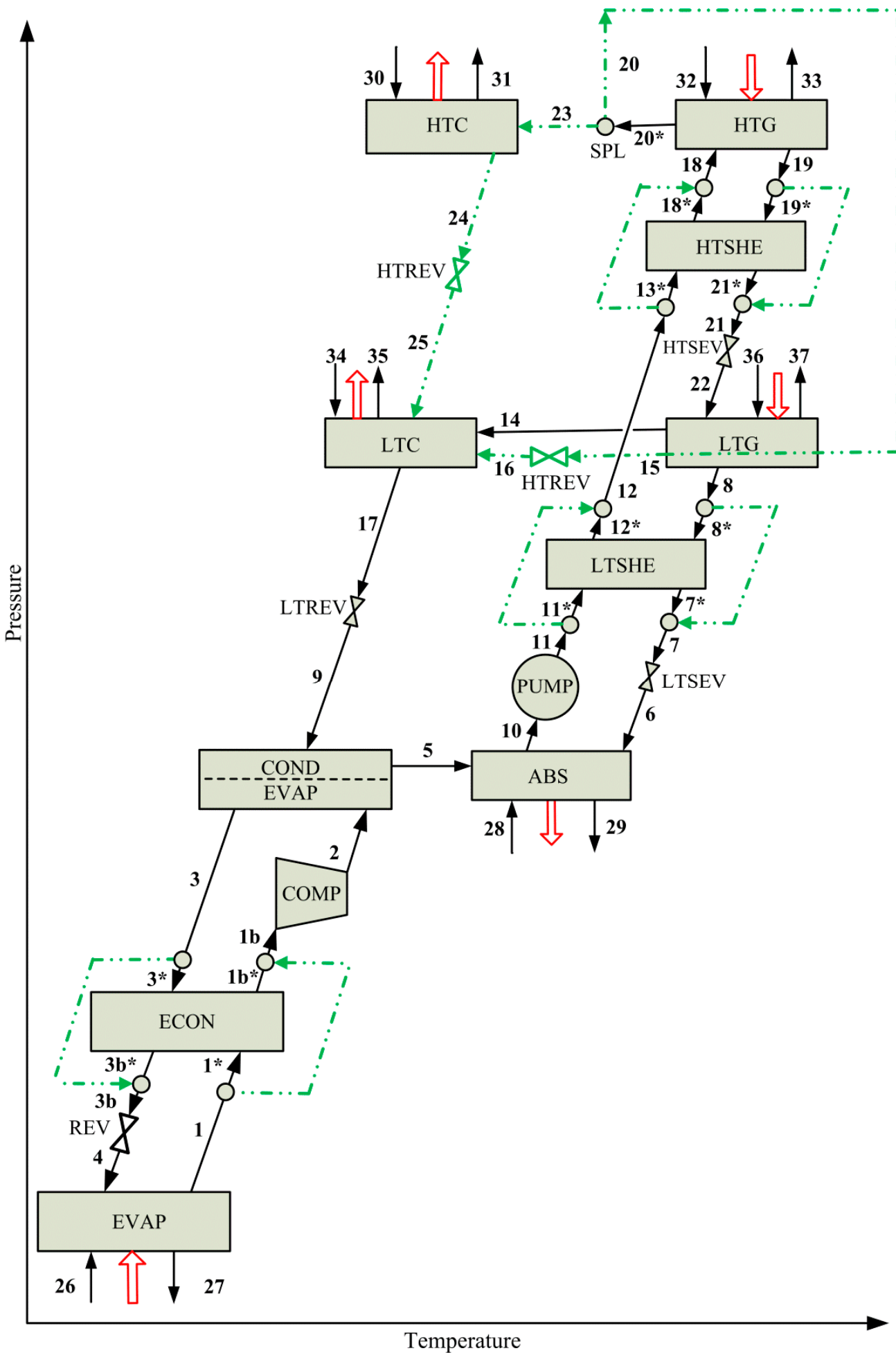

Figure 3. Schematic of the superstructure of the vapor compression-absorption cascade refrigeration system VCACRS, which is formed by a series flow double-effect $\mathrm{H}_{2} \mathrm{O}$-LiBr VARS and a simple VCRS operated with R134a. 


\section{Modeling}

\subsection{Process Model}

The mathematical model includes the mass and energy balances for each system component and the calculation of the corresponding heat transfer areas and driving forces. The considered complete mathematical model of VCACRS combines a model of double-effect $\mathrm{H}_{2} \mathrm{O}-\mathrm{LiBr}$ VARS [11] and a model of a simple R134a VCRS.

\subsubsection{Definitions}

Let SC be the set of the system components $\mathrm{k}$ :

$$
\mathrm{SC}=\left\{\begin{array}{l}
\text { EVAP, COMP, COND/EVAP, REV, ECON, ABS, PUMP }, \\
\text { LTG, HTG, LTC, LTREV, LTSEV }, \text { HTSEV }
\end{array}\right\}
$$

Let SS represent the set of all system streams $i$ and $\mathrm{IN}_{\mathrm{k}}$ and $\mathrm{OUT}_{\mathrm{k}}$ the sets of the system streams $\mathrm{i}$ entering and leaving a system component $k$, respectively.

Let $\mathrm{M}, \mathrm{X}, \mathrm{Q}, \mathrm{W}$, and $\mathrm{H}$ be the mass flow rate $\left(\mathrm{kg} \cdot \mathrm{s}^{-1}\right)$, mass fraction $\left(\mathrm{kg} \cdot \mathrm{kg}^{-1}\right)$, heat load $(\mathrm{kW})$, power $(\mathrm{kW})$, and enthalpy flow rate $(\mathrm{kW})$.

\subsubsection{Steady-State Balances for the k-th System Component}

- Total mass balance:

$$
\sum_{i \in \mathrm{IN}_{\mathrm{k}}} \mathrm{M}_{\mathrm{i}, \mathrm{k}}-\sum_{\mathrm{i} \in \mathrm{OUT}_{\mathrm{k}}} \mathrm{M}_{\mathrm{i}, \mathrm{k}}=0, \forall \mathrm{k} \in \mathrm{SC}
$$

- $\quad$ Mass balance of component $\mathrm{j}=\mathrm{LiBr}$ :

$$
\sum_{\mathrm{i} \in \mathrm{IN}_{\mathrm{k}}} \mathrm{M}_{\mathrm{i}, \mathrm{k}} \cdot \mathrm{X}_{\mathrm{j}, \mathrm{i}, \mathrm{k}}-\sum_{\mathrm{i} \in \mathrm{OUT}_{\mathrm{k}}} \mathrm{M}_{\mathrm{i}, \mathrm{k}} \cdot \mathrm{X}_{\mathrm{j}, \mathrm{i}, \mathrm{k}}=0, \forall \mathrm{k} \in \mathrm{SC}, \mathrm{j}=\mathrm{LiBr}
$$

- $\quad$ Energy balance (with negligible potential and kinetic energy changes):

$$
\begin{aligned}
& \mathrm{Q}_{\mathrm{u}, \mathrm{k}}-\mathrm{W}_{\mathrm{k}}+\sum_{\mathrm{i} \in \mathrm{IN}_{\mathrm{k}}} \mathrm{H}_{\mathrm{i}, \mathrm{k}}-\sum_{\mathrm{i} \in \mathrm{OUT}_{\mathrm{k}}} \mathrm{H}_{\mathrm{i}, \mathrm{k}}=0, \forall \mathrm{k} \in \mathrm{SC} \\
& \mathrm{Q}_{\mathrm{u}, \mathrm{k}}= \pm\left(\mathrm{H}_{\mathrm{u}, \mathrm{in}, \mathrm{k}}-\mathrm{H}_{\mathrm{u}, \text { out }, \mathrm{k}}\right)
\end{aligned}
$$

\subsubsection{Design Constraints}

- Heat transfer area of a system component $\mathrm{k}\left(\mathrm{HTA}_{\mathrm{k}}\right)$ :

$$
\mathrm{Q}_{\mathrm{k}}=\mathrm{U}_{\mathrm{k}} \cdot \mathrm{HTA}_{\mathrm{k}} \cdot \mathrm{LMTD}_{\mathrm{k}}, \forall \mathrm{k} \in \mathrm{SC}
$$

where $\mathrm{LMTD}_{\mathrm{k}}$ is the logarithmic mean temperature difference, which is calculated as:

$$
\mathrm{LMTD}_{\mathrm{k}}=\frac{\Delta \mathrm{T}_{\mathrm{k}}^{\mathrm{H}}-\Delta \mathrm{T}_{\mathrm{k}}^{\mathrm{C}}}{\ln \frac{\Delta \mathrm{T}_{\mathrm{k}}^{\mathrm{H}}}{\Delta \mathrm{T}_{\mathrm{k}}^{\mathrm{C}}}}, \forall \mathrm{k} \in \mathrm{SC}
$$

$\Delta \mathrm{T}_{\mathrm{k}}^{\mathrm{H}}$ and $\Delta \mathrm{T}_{\mathrm{k}}^{\mathrm{C}}$ are the temperature differences at the hot and cold sides, respectively.

- $\quad$ Total heat transfer area of VCACRS (THTA):

$$
\mathrm{THTA}=\sum_{\mathrm{k}} \mathrm{HTA}_{\mathrm{k}}, \quad \forall \mathrm{k} \in \mathrm{SC}
$$


- Heat exchanger effectiveness factor $(\varepsilon)$ : The effectiveness factor $\varepsilon$ of the solution LTSHE (Equation (8)) and HTSHE (Equation (9)) is based on the strong solution side:

$$
\begin{gathered}
\varepsilon_{\text {LTSHE }}=\frac{\mathrm{M}_{11 *} \cdot \mathrm{X}_{11 *} \cdot\left(\mathrm{T}_{12 *}-\mathrm{T}_{11 *}\right)}{\mathrm{M}_{8 *} \cdot \mathrm{X}_{8 *} \cdot\left(\mathrm{T}_{8 *}-\mathrm{T}_{11 *}\right)} \\
\varepsilon_{\text {HTSHE }}=\frac{\mathrm{M}_{13 *} \cdot \mathrm{X}_{13 *} \cdot\left(\mathrm{T}_{18 *}-\mathrm{T}_{13 *}\right)}{\mathrm{M}_{19 *} \cdot \mathrm{X}_{19 *} \cdot\left(\mathrm{T}_{19 *}-\mathrm{T}_{13 *}\right)}
\end{gathered}
$$

- Inequality constraints on stream temperatures: Inequality constraints are added to avoid temperature crosses in the system components. For instance, Equations (10) and (11) are considered for LTC, where $\delta$ is a small (positive) value (in this case $\delta=0.1$ ). Similar inequality constraints are considered for the remaining system components.

$$
\begin{aligned}
& \mathrm{T}_{35} \geq \mathrm{T}_{14}+\delta \\
& \mathrm{T}_{34} \geq \mathrm{T}_{17}+\delta
\end{aligned}
$$

- $\quad$ Other modeling considerations:

The model also includes the mass balance corresponding to the splitter SPL (Equation (12)), which allows to optionally consider the heat integration between HTG and LTG in some candidate configurations.

$$
\mathrm{M}_{20 *}=\mathrm{M}_{20}+\mathrm{M}_{23}
$$

According to Equation (12), if $\mathrm{M}_{23}=0$, then this implies that HTC is removed and, consequently, the energy contained in stream $20^{*}$ is transferred in LTG through stream 20.

The elimination (or selection) of LTSHE and HTSHE can be directly dealt with the values of their effectiveness factors ( $\varepsilon_{\text {LTSHE }}$ and $\varepsilon_{\text {HTSHE}}$, respectively), Equations (8) and (9).

According to Equation (8), if $\mathrm{T}_{12^{*}}=\mathrm{T}_{11^{*}}$ (no heat transfer), then $\eta_{\mathrm{LTSHE}}=0$. In analogy, in Equation (9), if $\mathrm{T}_{18^{*}}=\mathrm{T}_{13^{*}}$ (no heat transfer), then $\eta_{\text {HTSHE }}=0$. From this analysis, it can be concluded that the consideration of both $\eta_{\text {LTSHE }}$ and $\eta_{\text {HTSHE }}$ as optimization variables with proper lower and upper bounds ( $1 \times 10^{-3} \%$ and $99.0 \%$, respectively) makes it unnecessary to propose bypass streams (as shown in Figure 3) to eliminate LTSHE and HTSHE from a given configuration. The mathematical formulation of bypass streams would require the inclusion of binary decision variables and, consequently, the transformation of the NLP model into a MINLP model.

In summary, Equations (8), (9) and (12) allow that the candidate process configurations to be embedded and contemplated simultaneously in the mathematical model, whose solution provides the optimal one.

\subsection{Objective Function}

The objective function is the minimization of the total heat transfer area of the system (THTA) to obtain a evaporator temperature and refrigeration capacity of $-17.0^{\circ} \mathrm{C}$ and $50.00 \mathrm{~kW}$, respectively, using steam at $130.0^{\circ} \mathrm{C}$ and cooling water at $25.0^{\circ} \mathrm{C}$ as utilities. The optimization problem is formulated as follows:

$$
\begin{aligned}
& \text { Min (THAT) } \\
& \text { s.t. } \\
& \left\{\begin{array}{l}
\text { Eqs. (1)- }(12) \\
\text { Property estimation expressions } \\
\mathrm{Q}_{\text {EVAP }}=50.00 \mathrm{~kW} \\
\mathrm{~T}_{\text {EVAP }}=-17.0^{\circ} \mathrm{C} \\
\mathrm{T}_{\text {steam }}=130.0{ }^{\circ} \mathrm{C}, \mathrm{T}_{\text {cooling water }}=25.0^{\circ} \mathrm{C}
\end{array}\right.
\end{aligned}
$$




\section{Results and Discussion}

The optimization model was implemented in the platform GAMS v.23.6.5 [37] and solved with the solver CONOPT 3 v.3.14W [38].

\subsection{Model Verification}

Before solving the optimization problem stated in the previous section, the proposed model was succesfully verified using the data reported by Colorado and Rivera [31], which is here used as a reference case (referred to as the Colorado and Rivera's solution 'CRS'). To this end, it was necessary to set certain numerical values to consider the same configuration and operating conditions as in [31]. Tables 1 and 2 compare the model's output results with the solution reported in [31] for the analyzed system operating with R134a in VCRS and $\mathrm{H}_{2} \mathrm{O}-\mathrm{LiBr}$ in VARS. The values that were fixed are marked with $\left(^{a}\right)$ in these tables.

Table 1. Model validation. Comparison of mass flow rates $(\mathrm{M})$, temperatures $(\mathrm{T})$, pressures $(\mathrm{P})$, and $\mathrm{LiBr}$ solution concentrations $(\mathrm{X})$ of some representative process streams between the model outputs and reported data [31]. $\left(\mathrm{T}_{\mathrm{EVAP}}=-17.0^{\circ} \mathrm{C}, \mathrm{T}_{\mathrm{HTG}}=120.0^{\circ} \mathrm{C}, \mathrm{Q}_{\mathrm{EVAP}}=50.00 \mathrm{~kW}\right)$.

\begin{tabular}{ccccccccc}
\hline & \multicolumn{2}{c}{$\mathbf{M}\left(\mathbf{k g} \cdot \mathbf{s}^{-1}\right)$} & \multicolumn{2}{c}{$\mathbf{T}\left({ }^{\circ} \mathbf{C}\right)$} & \multicolumn{2}{c}{$\mathbf{P}(\mathbf{k P a})$} & \multicolumn{2}{c}{$\mathbf{X}(\% \mathbf{p} / \mathbf{p})$} \\
\hline Stream & Ref. [31] & This Work & Ref. [31] & This Work & Ref. [31] & This Work & Ref. [31] & This Work \\
\hline 1 & 0.267 & 0.268 & -17.0 & $-17.0^{\text {a }}$ & 150.8 & 150.387 & - & - \\
$1 \mathrm{~b}$ & 0.267 & 0.268 & 4.7 & 4.4 & 150.8 & 150.387 & - & - \\
2 & 0.267 & 0.268 & 49.9 & 50.1 & 472.9 & 470.998 & - & - \\
3 & 0.267 & 0.268 & 14.0 & $14.0^{\mathrm{a}}$ & 472.9 & 470.998 & - & - \\
3b & 0.267 & 0.268 & 1.0 & $1.0^{\mathrm{a}}$ & 472.9 & 470.998 & - & - \\
5 & 0.025 & 0.025 & 7.0 & 6.4 & 1.0 & 0.957 & - & - \\
6 & 0.266 & 0.255 & 47.6 & 44.4 & 1.0 & 0.957 & 58.9 & 58.569 \\
8 & 0.266 & 0.255 & 77.1 & 76.4 & 5.6 & $5.600^{\mathrm{a}}$ & 58.9 & 58.569 \\
10 & 0.291 & 0.280 & 35.0 & 34.1 & 1.0 & 0.958 & 53.8 & 53.498 \\
14 & 0.011 & $0.011^{\mathrm{a}}$ & 77.1 & 76.4 & 5.6 & $5.600^{\mathrm{a}}$ & - & - \\
18 & 0.291 & 0.280 & 99.0 & 102.3 & 42.1 & 43.638 & 53.8 & 53.498 \\
19 & 0.278 & 0.266 & 120.0 & $120.0^{\mathrm{a}}$ & 42.1 & 43.638 & 56.3 & 56.054 \\
\hline
\end{tabular}

Table 2. Model validation. Comparison of heat loads (Q), compressor work (W), and coefficients of performance (COP) between the model outputs and reported data [31] $\left(\mathrm{T}_{\mathrm{EVAP}}=-17.0{ }^{\circ} \mathrm{C}\right.$, $\left.\mathrm{T}_{\mathrm{HTG}}=120.0^{\circ} \mathrm{C}, \mathrm{Q}_{\mathrm{EVAP}}=50.00 \mathrm{~kW}\right)$.

\begin{tabular}{ccc}
\hline Item & Ref. [31] & This Work \\
\hline Heat load (kW) & & \\
- High-temperature generator, HTG & 45.80 & 45.10 \\
- Absorber, ABS & 72.63 & 72.414 \\
- Condenser, COND & 32.27 & 32.150 \\
- Evaporator, EVAP & 50.00 & $50.00^{\mathrm{a}}$ \\
\hline Work (kW) & & \\
- Compressor, COMP & 9.10 & 9.464 \\
\hline COP (dimensionless) & & \\
- VARS cycle & 1.29 & 1.312 \\
- VCRS cycle & 5.49 & 5.283 \\
- VCRS-VARS cascade cycle & 0.91 & 0.916 \\
\hline$\quad$ a Fixed value.
\end{tabular}

${ }^{\mathrm{a}}$ Fixed value.

From the comparison of values presented in Tables 1 and 2, it can be concluded that the results obtained with the implemented model is in agreement with the data reported in [31]. 


\subsection{Optimization Results}

Table 3 lists the main model parameters with the numerical values.

Table 3. Numerical values of the model parameters.

\begin{tabular}{cc}
\hline Parameter & Value \\
\hline Cooling capacity $(\mathrm{kW})$ & 50.00 \\
\hline Utility inlet/outlet temperature $\left({ }^{\circ} \mathrm{C}\right)$ : & \\
- Cooling water in condensers and absorbers & $25.0 / 32.0$ \\
- Steam in generators & 130.0 \\
\hline Overall heat transfer coefficient $\left(\mathrm{kW} \cdot \mathrm{m}^{-2} \cdot{ }^{\circ} \mathrm{C}^{-1}\right):$ & \\
- Evaporator, $\mathrm{U}_{\mathrm{EVAP}}$ & 1.50 \\
- Absorber, $\mathrm{U}_{\mathrm{ABS}}$ & 0.70 \\
- Condenser, $\mathrm{U}_{\mathrm{COND}}$ & 2.50 \\
- Generator, $\mathrm{U}_{\mathrm{GEN}}$ & 1.50 \\
- Cascade condenser & 0.55 \\
- Solution heat exchanger, $\mathrm{U}_{\mathrm{SHE}}$ & 1.00 \\
\hline
\end{tabular}

Figure 4 illustrates the optimal configuration selected from the proposed superstructure and the properties of the process streams entering and leaving each process component, and Table 4 reports the optimal values of the heat transfer area, heat load, and driving force of each system component. This optimal solution is hereafter referred to as 'OS'. As shown in Figure 4, the components HTC and HTSHE were removed from the proposed superstructure. No fraction of refrigerant separated in HTG is send to HTC, i.e., the refrigerant is completely used in LTG as the heating medium, where no (external) heating utility is required. Regarding HTSHE, the optimal value of its effectiveness factor $\varepsilon_{\mathrm{HTSHE}}$ is $6.6 \times 10^{-28}$ because the temperature difference of the strong $\mathrm{LiBr}$ solution streams 19 and 21 at the inlet and outlet of HTSHE, respectively, is practically null. However, LTSHE is selected in the optimal solution with an optimal $\varepsilon_{\text {LTSHE }}$ value of $40.3 \%$. The temperature difference of the strong $\mathrm{LiBr}$ solution streams 8 and 7 at the inlet and outlet of LTSHE, respectively, is $19.2 \mathrm{~K}$, and that of the weak solution streams 12 and 11 at the outlet and inlet of LTSHE, respectively, is $16.6 \mathrm{~K}$.

This obtained configuration is different from the configurations reported so far in the literature for combinations of double-effect $\mathrm{H}_{2} \mathrm{O}-\mathrm{LiBr}$ VAR and VCR systems. According to Table 4, it requires a minimal THTA value of $24.980 \mathrm{~m}^{2}$, which is optimally distributed among the process units as is indicated in Figure 5.

The component ABS requires the largest heat transfer area $\left(10.339 \mathrm{~m}^{2}\right)$, which represents $41.4 \%$ of THTA, followed by COND/EVAP, which allowed coupling the two refrigeration systems, representing $20.8 \%\left(5.225 \mathrm{~m}^{2}\right)$ of THTA. The components LTC, EVAP, and LTG require similar heat transfer areas $\left(2.959,2.331\right.$, and $\left.2.190 \mathrm{~m}^{2}\right)$ contributing with $11.8 \%, 9.3 \%$, and $8.8 \%$ of THTA, respectively. The heat transfer area required in LTSHE is higher than twice the required in ECON $\left(0.457 \mathrm{~m}^{2} \mathrm{vs} .0 .191 \mathrm{~m}^{2}\right)$. The optimal LiBr concentration values of the strong solutions at LTG and HTG are $58.379 \%$ and $55.023 \%$, respectively, while the corresponding to the weak solution at ABS is $53.669 \%$. The optimal operating pressures at LTG and HTG are 5.69 and $47.307 \mathrm{kPa}$, respectively. With regard to heating utility, which is provided by steam, the system requires a mass flow rate of $0.029 \mathrm{~kg} \cdot \mathrm{s}^{-1}$ at $130.00{ }^{\circ} \mathrm{C}$. Regarding the cooling utility, which is provided by water, the system requires a mass flow rate of $1.514 \mathrm{~kg} \cdot \mathrm{s}^{-1}$ in LTC and $2.656 \mathrm{~kg} \cdot \mathrm{s}^{-1}$ in ABS, with inlet and outlet temperatures of 25.0 and $32.0^{\circ} \mathrm{C}$, respectively. The compressor COMP requires an amount of electrical power of $8.138 \mathrm{~kW}$. The specified refrigeration capacity of $50.00 \mathrm{~kW}$ is obtained by evaporating $0.272 \mathrm{~kg} \cdot \mathrm{s}^{-1}$ of $\mathrm{R} 134 \mathrm{a}$ at $150.390 \mathrm{kPa}$ and $-17.0^{\circ} \mathrm{C}$. The refrigerant R134a of the VCRS transfers heat to the refrigerant $\mathrm{H}_{2} \mathrm{O}$ of the VARS in COND/EVAP at a heat flow rate of $58.138 \mathrm{~kW}$. The total mass flow rate of refrigerant $\mathrm{H}_{2} \mathrm{O}$ evaporated in the VARS cycle is $0.025 \mathrm{~kg} \cdot \mathrm{s}^{-1}$, of which $8.0 \times 10^{-3} \mathrm{~kg} \cdot \mathrm{s}^{-1}$ is obtained in HTG and $0.017 \mathrm{~kg} \cdot \mathrm{s}^{-1}$ in LTG. 


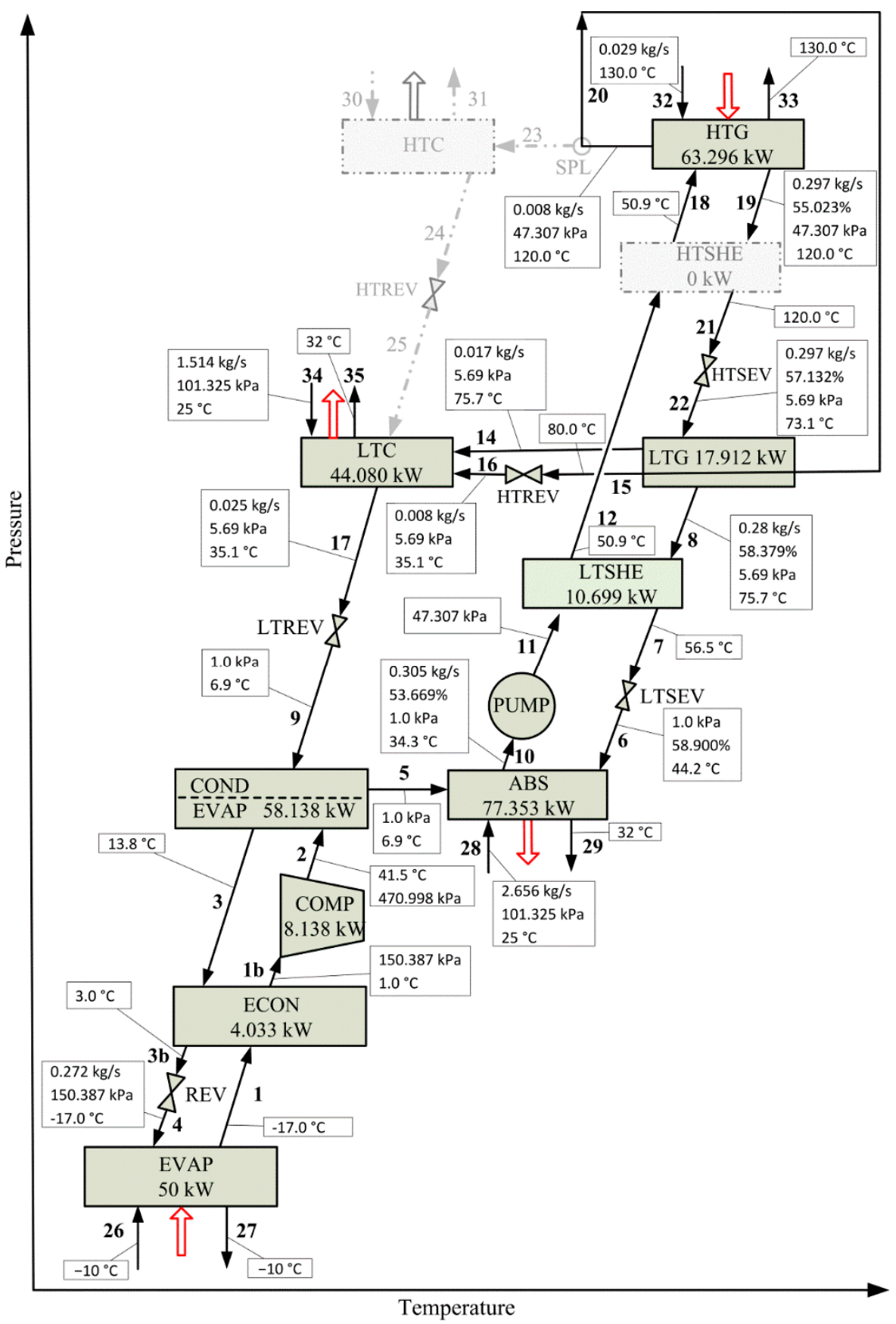

Figure 4. Optimal solution OS. Process configuration resulting from the superstructure proposed in Figure 3 by minimizing the total heat transfer area (THTA) for a refrigeration capacity of $50.00 \mathrm{~kW}$.

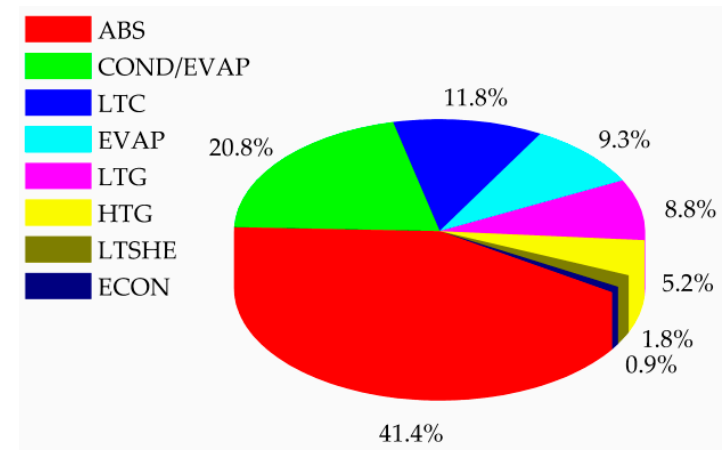

Figure 5. Optimal solution OS. Distribution of the total heat transfer area (THTA) among the system components obtained by minimizing THTA, for a refrigeration capacity of $50.00 \mathrm{~kW}$. 
Table 4. Optimal solution OS. Heat loads (Q), heat transfer areas (HTA), and logarithmic mean temperature differences (LMTD) obtained by minimizing the total heat transfer area (THTA) for a cooling capacity of $50.00 \mathrm{~kW}$.

\begin{tabular}{cccc}
\hline Component & HTA $\left.\mathbf{( m}^{\mathbf{2}}\right)$ & $\mathbf{Q} \mathbf{( k W )}$ & LMTD (K) \\
\hline ABS & 10.339 & 77.353 & 10.7 \\
\hline COND/EVAP & $\begin{array}{c}0.277^{\mathrm{a}} / 4.948^{\mathrm{b}} \\
5.225^{\mathrm{c}}\end{array}$ & $\begin{array}{c}7.068^{\mathrm{a}} / 51.070^{\mathrm{b}} \\
58.138^{\mathrm{c}}\end{array}$ & $16.9^{\mathrm{a}} / 6.9^{\mathrm{b}}$ \\
\hline LTC & 2.959 & 44.080 & 6.0 \\
\hline EVAP & 2.331 & 50.00 & 7.1 \\
\hline LTG & 2.190 & 17.912 & 5.4 \\
\hline HTG & 1.288 & 63.296 & 32.7 \\
\hline LTSHE & 0.457 & 10.699 & 23.4 \\
\hline ECON & 0.191 & 4.033 & 16.2 \\
\hline HTSHE & $1.53 \times 10^{-24}$ & $\begin{array}{c}1.060 \times 10^{-22} \\
(\varepsilon=0)\end{array}$ & 69.0 \\
\hline HTC & - & - & - \\
\hline Total & $\begin{array}{c}(\mathrm{THTA}) \\
\left({ }^{\mathrm{a}} \text { Subcooling process; }{ }^{\mathrm{b}} \text { condensation process; }{ }^{\mathrm{c}} \text { total. }\right.\end{array}$
\end{tabular}

Compared to the reference case CRS (Section 5.1), the THTA value decreased $16.7 \%\left(5.015 \mathrm{~m}^{2}\right.$, from 30.000 to $24.980 \mathrm{~m}^{2}$ ) implying an increase of $18.19 \mathrm{~kW}$ in the heat load in HTG and a decrease of $1.33 \mathrm{~kW}$ in COMP. The obtained values determine a COP value of 0.700 , which is 0.216 less than that corresponding to CRS (0.916). Then, it is interesting to solve the same optimization problem, i.e., to minimize THTA but now considering the COP value estimated for CRS. This optimal solution is hereafter referred to as 'SubOS', which is a suboptimal solution with respect to the optimal solution OS.

\section{Comparison between the Optimal Solution SubOS and the Reference Case CRS}

This section presents a comparison between the optimal solution obtained by the superstructure-based model and that corresponding to the reference case CRS [31]. To this end, the optimization model is solved for the same values of refrigeration capacity $(50.00 \mathrm{~kW})$, heat load in HTG $(45.10 \mathrm{~kW})$ and mechanical power required by the compressor $(9.464 \mathrm{~kW})$, as considered in the reference case.

Figures 6 and 7 present the process configurations and the operating conditions of each system component corresponding to CRS and SubOS, respectively. Table 5 compares the values of the heat load Q, heat transfer area HTA and driving force DF of each system component and the total heat transfer area THTA between CRS and SubOS cases. 


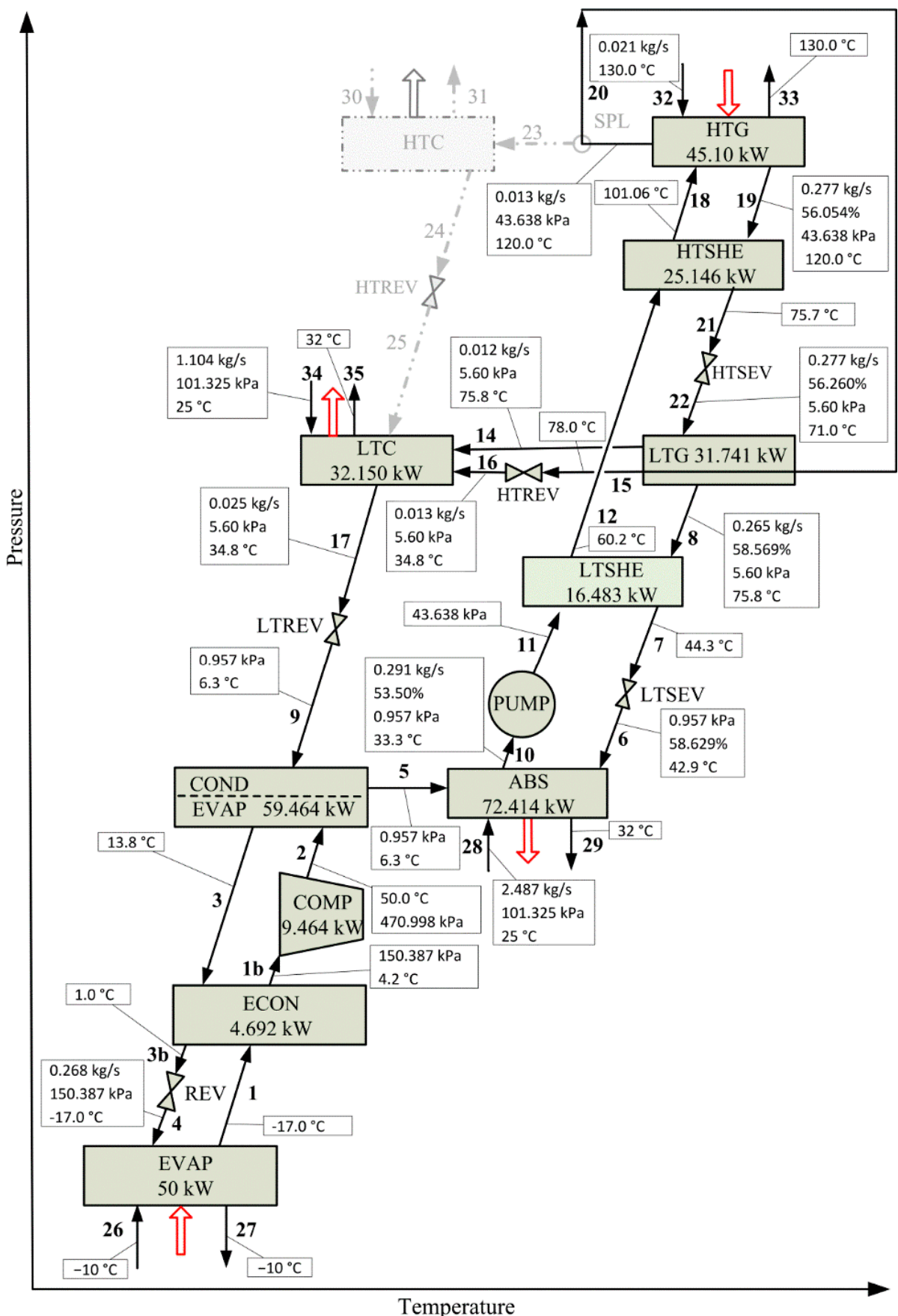

Figure 6. Reference case CRS. Process configuration and operating conditions reported in [31] for a specified refrigeration capacity of $50.00 \mathrm{~kW}$, a heat load of $45.10 \mathrm{~kW}$ in HTG, and a mechanical power of $9.464 \mathrm{~kW}$ in COMP. 


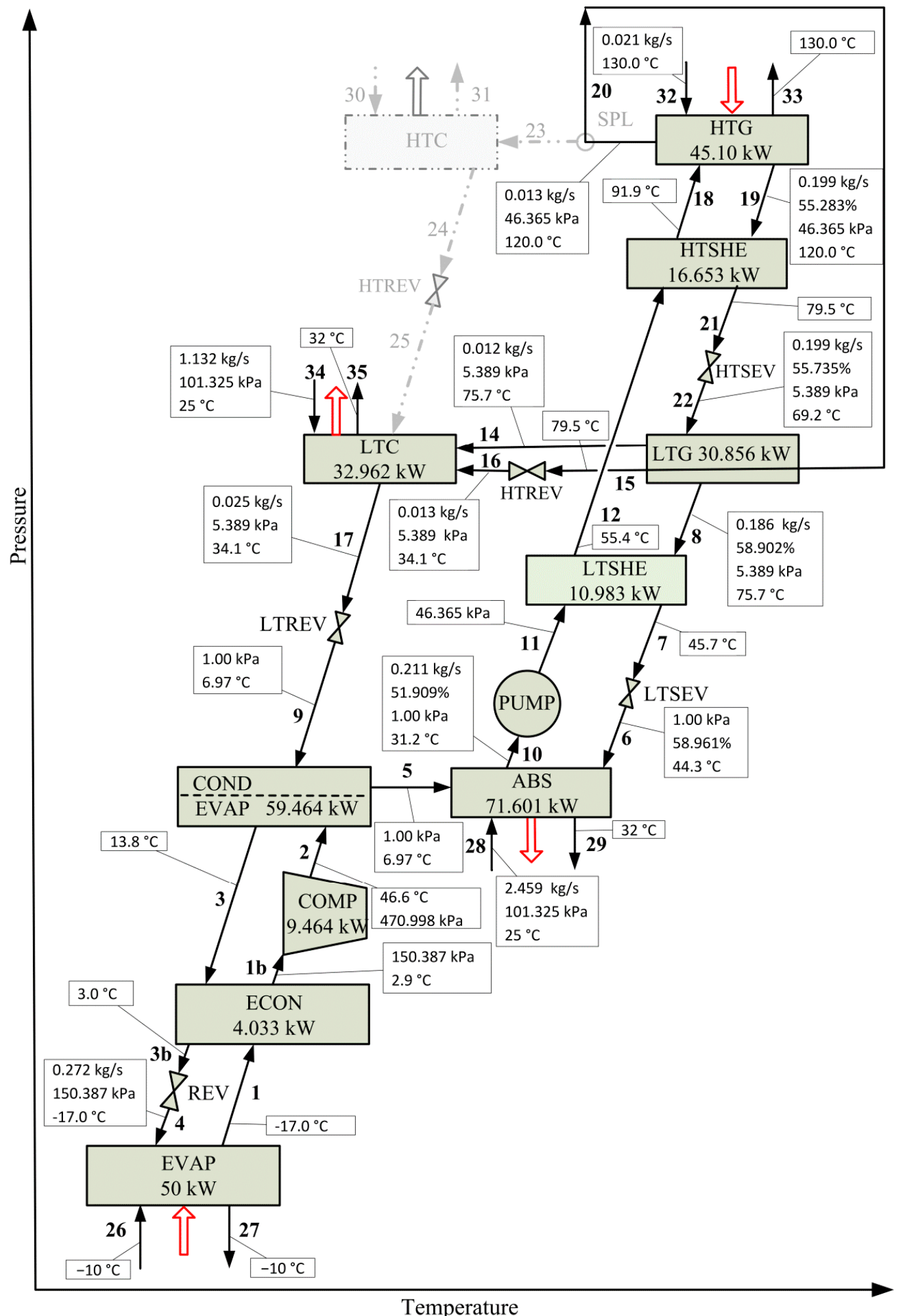

Figure 7. Optimal solution SubOS. Process configuration and operating conditions obtained for a refrigeration capacity of $50.00 \mathrm{~kW}$, a heat load of $45.10 \mathrm{~kW}$ in HTG, and a mechanical power of $9.464 \mathrm{~kW}$ in COMP.

For the same input energy in HTG and mechanical power in COMP used in CRS, a main result to highlight is that HTSHEX is now selected by SubOS and THTA decreases with respect to CRS. From Table 5, it can be observed several changes in the operating conditions of the system components 
compared to CRS. The THTA required in SubOS is $7.3 \%$ smaller than that required in CRS $\left(27.824 \mathrm{~m}^{2} \mathrm{vs}\right.$. $30.000 \mathrm{~m}^{2}$ ). Despite the fact that COND/EVAP, ABS, and LTC increase their heat transfer areas compared to CRS (in total $1.543 \mathrm{~m}^{2}$, from $17.881 \mathrm{~m}^{2}$ to $19.422 \mathrm{~m}^{2}$ ), the remaining system components HTG, LTG, COND, ECON, LSHEX, and HSHEX decrease their heat transfer areas (in total $3.719 \mathrm{~m}^{2}$, from 9.789 $\mathrm{m}^{2}$ to $6.070 \mathrm{~m}^{2}$ ), thus resulting in a net decrease of $2.176 \mathrm{~m}^{2}$. For instance, although the heat load in COND/EVAP is the same in both configurations $(59.463 \mathrm{~kW})$, the respective heat transfer area required in SubOS is $5.6 \%$ higher than that required in CRS $\left(11.438 \mathrm{~m}^{2}\right.$ vs. $\left.10.828 \mathrm{~m}^{2}\right)$ because the associated driving force in SubOS is smaller than that in CRS ( $18.5 \mathrm{~K}$ vs. $20.3 \mathrm{~K}$ for the subcooling process and $6.8 \mathrm{~K}$ vs. $7.5 \mathrm{~K}$ for the condensation process, as shown in Table 5). The differences in the driving force values in both solutions is because of the different inlet temperatures of the refrigerant R134a in the COND/EVAP. The operating temperatures are 46.6 and $50.0^{\circ} \mathrm{C}$ in SubOS and CRS, respectively, while the same operating pressures are considered in both solutions (470.998 $\mathrm{kPa}$ in COND/EVAP and 150.387 in EVAP). However, it is necessary to increase the refrigerant flow in SubOS by $0.004 \mathrm{~kg} \cdot \mathrm{s}^{-1}$ (from 0.268 to $0.272 \mathrm{~kg} \cdot \mathrm{s}^{-1}$ ) to provide the mechanical power required in COMP $(9.464 \mathrm{~kW}$ ). As the temperature leaving REV in SubOS is $2.0^{\circ} \mathrm{C}$ higher than CRS, the vapor quality of the stream entering EVAP valve increases by 0.013 (from 0.113 in CRS to 0.126 in SubOp) in order to maintain both the isoenthalpic condition in REV and the specified refrigeration capacity $(50.00 \mathrm{~kW})$.

The heat load in ABS in SubOS is lower than that in CRS (71.601 kW vs. $72.414 \mathrm{~kW})$ but the required area is larger $\left(11.438 \mathrm{~m}^{2}\right.$ vs. $\left.10.828 \mathrm{~m}^{2}\right)$ because the driving force in SubOS is lower than that in CRS $(8.9 \mathrm{~K}$ vs. $9.5 \mathrm{~K})$. A different behavior is observed for LTG between the heat load, heat transfer area, and driving force. The heat load in LTG in SubOS is $0.885 \mathrm{~kW}$ lower than that in CRS (30.856 kW vs. $31.741 \mathrm{~kW})$ and the heat transfer area is $1.956 \mathrm{~m}^{2}$ lower $\left(3.164 \mathrm{~m}^{2}\right.$ vs. $\left.5.120 \mathrm{~m}^{2}\right)$ because the driving force in SubOS is $2.4 \mathrm{~K}$ higher than that in CRS (6.5 K vs. $4.1 \mathrm{~K})$. This behavior is also observed for HTG. With respect to the solution heat exchangers, the total heat exchanged in HTSHE and LTSHE in CRS is $13.993 \mathrm{~kW}$ higher than that in SubOS (41.629 kW vs. $27.636 \mathrm{~kW})$, requiring $1.433 \mathrm{~m}^{2}$ more of heat transfer area $\left(2.710 \mathrm{~m}^{2}\right.$ vs. $\left.1.277 \mathrm{~m}^{2}\right)$.

Regarding the LiBr solution concentration values, SubOS shows values lower than CRS, with the particularity that the concentration difference between the weak and strong solutions at HTG in SubOS is higher than that in CRS (3.374\% vs. $2.554 \%$ ). The $\mathrm{LiBr}$ solution concentration values leaving the LTG are almost similar in both solutions (58.569\% in CRS and 58.902\% in SubOS).

An important result to note is that the total mass flow rates of $\mathrm{H}_{2} \mathrm{O}$ refrigerant circulating in the absorption subsystem are the same in both solutions. However, the flowrates of the weak and strong LiBr solution in SubOS are lower than those in CRS (weak: $0.212 \mathrm{vs.} 0.291 \mathrm{~kg} \cdot \mathrm{s}^{-1}$; strong: $0.199 \mathrm{vs}$. $\left.0.277 \mathrm{~kg} \cdot \mathrm{s}^{-1}\right)$. While the operating pressure at HTG in SubOS is higher than that in CRS $(46.365 \mathrm{kPa}$ vs. $43.638 \mathrm{kPa})$ and it is almost similar at ABS (0.957 $\mathrm{kPa}$ in CRS and $1.000 \mathrm{kPa}$ in SubOS) and LTG (5.600 kPa in CRS and $5.389 \mathrm{kPa}$ in SubOS). Although the total flowrate of cooling water required in ABS and COND is the same in both solutions $\left(3.591 \mathrm{~kg} \cdot \mathrm{s}^{-1}\right.$ ) - as the heat loads at HTG and EVAP, mechanical power at COMP, and inlet and oultet temperatures of the cooling water are the same-the individual cooling requiriments in ABS and COND are different in both solutions. In SubOS, COND and $A B S$ require $1.132 \mathrm{~kg} \cdot \mathrm{s}^{-1}$ and $2.459 \mathrm{~kg} \cdot \mathrm{s}^{-1}$ of cooling water, respectively; while, in CRS, they require $1.104 \mathrm{~kg} \cdot \mathrm{s}^{-1}$ y $2.487 \mathrm{~kg} \cdot \mathrm{s}^{-1}$, respectively.

As a summary of the comparative analysis between both configurations, it can be concluded that the obtained SubOS solution is preferred over the reported CRS solution as the former requires less THTA for the same requirements of heating and cooling utilities (steam and cooling water, respectively), thus implying a lower total annual cost (investment plus operating costs). 
Table 5. Comparison of heat load (Q), heat transfer area (HTA), and driving force (DF) values between the reference case (CRS) [31] and the optimal solution obtained in this work (SubOS), for a refrigeration capacity of $50.00 \mathrm{~kW}$.

\begin{tabular}{|c|c|c|c|c|c|c|}
\hline \multirow[b]{2}{*}{ Component } & \multicolumn{3}{|c|}{ Ref. [31] } & \multicolumn{3}{|c|}{ SubOS (This Work) } \\
\hline & $Q(\mathrm{~kW})$ & HTA $\left(m^{2}\right)$ & DF (K) & $Q(\mathrm{~kW})$ & HTA $\left(m^{2}\right)$ & DF (K) \\
\hline EVAP & 50.00 & 2.331 & 7.150 & 50.00 & 2.331 & 7.150 \\
\hline COND/EVAP & $\begin{array}{c}9.127^{\mathrm{a}} / 50.336^{\mathrm{b}} \\
59.463^{\mathrm{c}} \\
\end{array}$ & $\begin{array}{c}0.299^{\mathrm{a}} / 4.469^{\mathrm{b}} \\
4.768^{\mathrm{c}}\end{array}$ & $20.3^{\mathrm{a}} / 7.5^{\mathrm{b}}$ & $\begin{array}{c}8.396^{\mathrm{a}} / 51.068^{\mathrm{b}} \\
59.464^{\mathrm{c}}\end{array}$ & $\begin{array}{c}0.302^{\mathrm{a}} / 4.948^{\mathrm{b}} \\
5.25^{\mathrm{c}}\end{array}$ & $18.5^{\mathrm{a}} / 6.8^{\mathrm{b}}$ \\
\hline ABS & 72.414 & 10.828 & 9.5 & 71.601 & 11.438 & 8.9 \\
\hline LTSHE & 16.483 & 1.247 & 13.2 & $\begin{array}{c}10.983(\varepsilon= \\
54.348 \%)\end{array}$ & 0.637 & 17.2 \\
\hline LTG & 31.741 & 5.120 & 4.1 & 30.856 & 3.164 & 6.5 \\
\hline HTSHE & 25.146 & 1.463 & 17.2 & $\begin{array}{c}16.653(\varepsilon= \\
56.542 \%)\end{array}$ & 0.64 & 26.0 \\
\hline HTG & 45.10 & 1.690 & 17.8 & 45.100 & 1.438 & 20.9 \\
\hline LTC & 32.150 & 2.285 & 5.629 & 32.962 & 2.735 & 4.8 \\
\hline ECON & 4.692 & 0.269 & 13.4 & 4.033 & 0.191 & 16.2 \\
\hline HTC & - & - & - & - & - & - \\
\hline Total & & 30.000 (THTA) & & & 27.824 (THTA) & \\
\hline
\end{tabular}

Finally, the influence of the heat load at HTG on the selection or elimination of the HTSHE and on the total heat transfer area THTA is investigated by keeping a refrigeration capacity of $50.00 \mathrm{~kW}$, in order to identify the input energy level that determines the elimintation of HTSHE from the optimal solutions. To this end, the heat load at HTG is parametrically varied from 45.10 to $63.00 \mathrm{~kW}$ and the mathematical optimization model is solved to find the minimal THTA value for each case. Figure 8 plots the minimal THTA vs. the heat load at HTG and Figure 9 shows the optimal percentage contribucion of each system component to THTA.

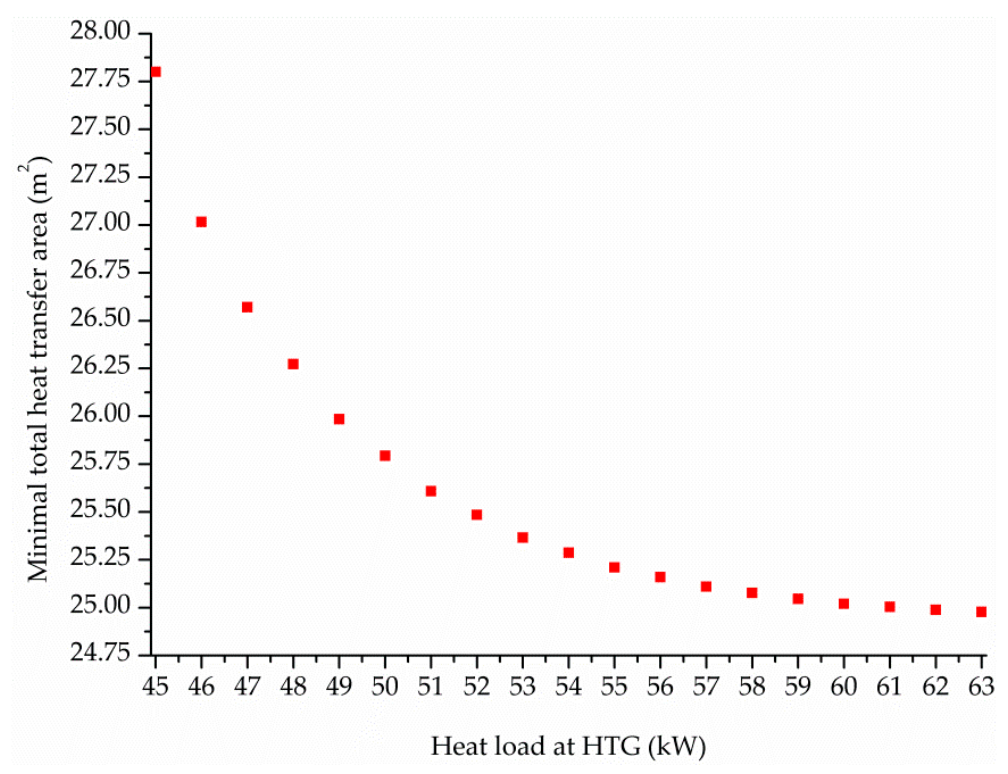

Figure 8. Minimal THTA vs. heat load at HTG for a refrigeration capacity of $50.00 \mathrm{~kW}$. 


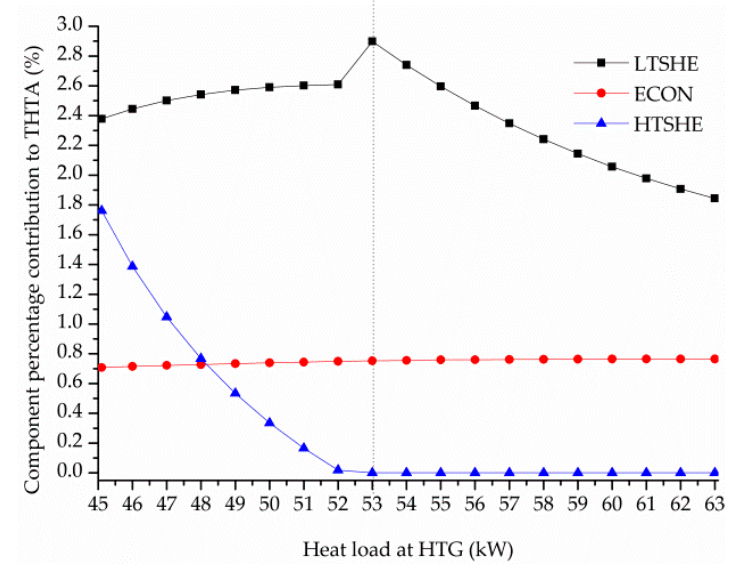

(a)

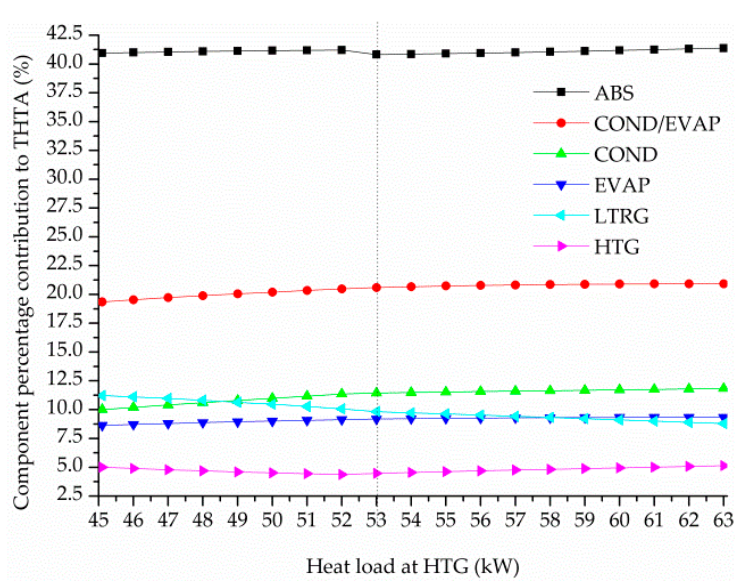

(b)

Figure 9. Optimal percentage contribution of each component to THTA vs. heat load at HTG, for a refrigeration capacity of $50.00 \mathrm{~kW}$. (a) LTSHEX, ECON, and HTSHEX, (b) ABS, COND/EVAP, COND, EVAP, LTG, and HTG.

As expected, the higher the heat load at HTG the lower the THTA (Figure 8). Regarding the selection or elimination of HTSHE from the process configuration, Figure 9a shows that HTSHE is included in the optimal solutions for HTG heat load values in the variation range between 45.00 and $52.00 \mathrm{~kW}$ and that it is removed from the optimal solutions for a HTG heat load value equal or higher than $53.00 \mathrm{~kW}$.

\section{Conclusions}

Superstructure-based optimization of a vapor compression-absorption cascade refrigeration system consisting of a series flow double-effect $\mathrm{H}_{2} \mathrm{O}-\mathrm{LiBr}$ absorption system and an R134a compression system, which embeds several candidate process configurations to consider the configuration as an optimization variable, was successfully addressed by applying nonlinear mathematical programming.

As a main result, a novel configuration of the combined process not previously reported in the literature-according to the best of our knowledge-was obtained when the total heat transfer area of the system was minimized. Two characteristics of the resulting optimal configuration are (a) the elimination of the high-temperature LiBr solution heat exchanger HTSHE; and (b) the energy integration between the high-temperature generator HTG and the low-temperature generator LTG, thus eliminating the presence of the (separated) high-temperature condenser HTC, i.e., no fraction of the refrigerant separated in HTG is sent to HTC since it is totally used in LTG as the heating medium, where no external heating utility is required to produce extra vapor at low temperature.

From a quantitative point of view, the component ABS shows the largest heat transfer area, which represents around $41 \%$ of the total heat transfer area. It is followed by COND/EVAP, which allowed coupling the two refrigeration systems by evaporating refrigerant $\mathrm{H}_{2} \mathrm{O}$ in the absorption cycle while condensing R134a in the compression cycle, which represents around $20 \%$ of the total heat transfer area.

Additionally, the obtained optimal solution was compared with the solution corresponding to a base configuration recently reported in the literature-used as a reference design-for the same coefficient of performance (COP), working fluids, refrigeration capacity and evaporator temperature (50.00 $\mathrm{kW}$ and $-17.0^{\circ} \mathrm{C}$, respectively). The comparison showed that the obtained minimal total heat transfer area is around $7.3 \%$ smaller than the required in the reference case.

Finally, the influence of the heat load at HTG on the total heat transfer area THTA and the selection or elimination of HTSHE for a same refrigeration capacity of $50 \mathrm{~kW}$ and a evaporator temperature of $-17.0^{\circ} \mathrm{C}$ was also investigated. The HTG heat load was parametrically varied from 45.0 to $63.0 \mathrm{~kW}$. It was found that HTSHE is included in the optimal solutions for HTG heat load values in the variation 
range between 45.00 and $52.00 \mathrm{~kW}$ and that it is removed from the optimal solutions for a HTG heat load value equal or higher than $53.00 \mathrm{~kW}$. The component HTC is always eliminated in the obtained optimal solutions.

Author Contributions: All authors contributed to the analysis of the results and to writing the manuscript. S.F.M. developed and implemented the mathematical optimization model in GAMS, collected and analyzed data, and wrote the first draft of the manuscript. All authors provided feedback to the content and revised the final draft. M.C.M. conceived and supervised the research. All authors have read and agreed to the published version of the manuscript.

Funding: The financial support from the National Scientific and Technical Research Council (Consejo Nacional de Investigaciones Científicas y Técnicas CONICET) and the National University of Technology (Universidad Tecnológica Nacional) from Argentina and the Technical University of Berlin is gratefully acknowledged. S.F.M. also acknowledges the financial support from the German Academic Exchange Service (DAAD) for his research visit at the TU Berlin under the Re-invitation Programme for Former Scholarship Holders (Funding Programm Number 57440916).

Conflicts of Interest: The authors declare no conflict of interest.

\section{References}

1. Coulomb, D. The Role of Refrigeration in the Global Economy. 29th Informatory Note on Refrigeration Technologies 2015. Available online: https://sainttrofee.nl/wp-content/uploads/2019/01/NoteTech_29-WorldStatistics.pdf (accessed on 10 November 2019).

2. Dincer, I. Refrigeration Systems and Applications, 3rd ed.; John Wiley \& Sons, Inc.: Chichester, UK, 2017; ISBN 978-1-119-23075-5.

3. She, X.; Cong, L.; Nie, B.; Leng, G.; Peng, H.; Chen, Y.; Zhang, X.; Wen, T.; Yang, H.; Luo, Y. Energy-efficient and -economic technologies for air conditioning with vapor compression refrigeration: A comprehensive review. Appl. Energy 2018, 232, 157-186. [CrossRef]

4. Yang, S.; Deng, C.; Liu, Z. Optimal design and analysis of a cascade LiBr/H2O absorption refrigeration/transcritical CO2 process for low-grade waste heat recovery. Energy Convers. Manag. 2019, 192, 232-242. [CrossRef]

5. Arshad, M.U.; Ghani, M.U.; Ullah, A.; Güngör, A.; Zaman, M. Thermodynamic analysis and optimization of double effect absorption refrigeration system using genetic algorithm. Energy Convers. Manag. 2019, 192, 292-307. [CrossRef]

6. Mussati, S.F.; Gernaey, K.V.; Morosuk, T.; Mussati, M.C. NLP modeling for the optimization of LiBr-H2O absorption refrigeration systems with exergy loss rate, heat transfer area, and cost as single objective functions. Energy Convers. Manag. 2016, 127, 526-544. [CrossRef]

7. Kaynakli, O.; Saka, K.; Kaynakli, F. Energy and exergy analysis of a double effect absorption refrigeration system based on different heat sources. Energy Convers. Manag. 2015, 106, 21-30. [CrossRef]

8. Garousi Farshi, L.; Mahmoudi, S.M.S.; Rosen, M.A.; Yari, M.; Amidpour, M. Exergoeconomic analysis of double effect absorption refrigeration systems. Energy Convers. Manag. 2013, 65, 13-25. [CrossRef]

9. Bereche, R.P.; Palomino, R.G.; Nebra, S. Thermoeconomic analysis of a single and double-effect $\mathrm{LiBr} / \mathrm{H} 2 \mathrm{O}$ absorption refrigeration system. Int. J. Thermodyn. 2009, 12, 89-96.

10. Mohtaram, S.; Chen, W.; Lin, J. Investigation on the combined Rankine-absorption power and refrigeration cycles using the parametric analysis and genetic algorithm. Energy Convers. Manag. 2017, 150, 754-762. [CrossRef]

11. Mussati, S.F.; Cignitti, S.; Mansouri, S.S.; Gernaey, K.V.; Morosuk, T.; Mussati, M.C. Configuration optimization of series flow double-effect water-lithium bromide absorption refrigeration systems by cost minimization. Energy Convers. Manag. 2018, 158, 359-372. [CrossRef]

12. Gebreslassie, B.H.; Medrano, M.; Boer, D. Exergy analysis of multi-effect water-LiBr absorption systems: From half to triple effect. Renew. Energy 2010, 35, 1773-1782. [CrossRef]

13. Chen, Q.; Zhou, L.; Yan, G.; Yu, J. Theoretical investigation on the performance of a modified refrigeration cycle with R170/R290 for freezers application. Int. J. Refrig. 2019, 104, 282-290. [CrossRef]

14. Baakeem, S.S.; Orfi, J.; Alabdulkarem, A. Optimization of a multistage vapor-compression refrigeration system for various refrigerants. Appl. Therm. Eng. 2018, 136, 84-96. [CrossRef] 
15. Yang, S.; Ordonez, J.C. Integrative thermodynamic optimization of a vapor compression refrigeration system based on dynamic system responses. Appl. Therm. Eng. 2018, 135, 493-503. [CrossRef]

16. Yang, S.; Ordonez, J.C.; Vargas, J. Constructal vapor compression refrigeration systems design. Int. J. Heat Mass Transf. 2017, 115, 754-768. [CrossRef]

17. Ma, W.; Fang, S.; Su, B.; Xue, X.; Li, M. Second-law-based analysis of vapor compression refrigeration cycles: Analytical equations for COP and new insights into features of refrigerants. Energy Convers. Manag. 2017, 138, 426-434. [CrossRef]

18. Zendehboudi, A.; Mota-Babiloni, A.; Makhnatch, P.; Saidur, R.; Sait, S.M. Modeling and multi-objective optimization of an R450A vapor compression refrigeration system. Int. J. Refrig. 2019, 100, 141-155. [CrossRef]

19. Zhao, L.; Cai, W.; Ding, X.; Chang, W. Model-based optimization for vapor compression refrigeration cycle. Energy 2013, 55, 392-402. [CrossRef]

20. Agarwal, S.; Arora, A.; Arora, B.B. Energy and exergy analysis of vapor compression-triple effect absorption cascade refrigeration system. Eng. Sci. Technol. 2019, in press. [CrossRef]

21. Patel, B.; Kachhwaha, S.S.; Modi, B. Thermodynamic Modelling and Parametric Study of a Two Stage Compression-Absorption Refrigeration System for Ice Cream Hardening Plant. Energy Procedia 2017, 109, 190-202. [CrossRef]

22. Jain, V.; Kachhwaha, S.S.; Sachdeva, G. Thermodynamic performance analysis of a vapor compression-absorption cascaded refrigeration system. Energy Convers. Manag. 2013, 75, 685-700. [CrossRef]

23. Cimsit, C.; Ozturk, I.T. Analysis of compression-Absorption cascade refrigeration cycles. Appl. Therm. Eng. 2012, 40, 311-317. [CrossRef]

24. Boyaghchi, F.A.; Mahmoodnezhad, M.; Sabeti, V. Exergoeconomic analysis and optimization of a solar driven dual-evaporator vapor compression-absorption cascade refrigeration system using water/CuO nanofluid. J. Clean. Prod. 2016, 139, 970-985. [CrossRef]

25. Chen, W.; Li, Z.; Sun, Q.; Zhang, B. Energy and exergy analysis of proposed compression-absorption refrigeration assisted by a heat-driven turbine at low evaporating temperature. Energy Convers. Manag. 2019, 191, 55-70. [CrossRef]

26. Xu, Y.; Jiang, N.; Pan, F.; Wang, Q.; Chen, G. Comparative study on two low-grade heat driven absorption-compression refrigeration cycles based on energy, exergy, economic and environmental (4E) analyses. Energy Convers. Manag. 2017, 133, 535-547. [CrossRef]

27. Salhi, K.; Korichi, M.; Ramadan, K.M. Thermodynamic and thermo-economic analysis of compression-absorption cascade refrigeration system using low-GWP HFO refrigerant powered by geothermal energy. Int. J. Refrig. 2018, 94, 214-229. [CrossRef]

28. Garousi Farshi, L.; Khalili, S.; Amirhossein, M. Thermodynamic analysis of a cascaded compression-Absorption heat pump and comparison with three classes of conventional heat pumps for the waste heat recovery. Appl. Therm. Eng. 2017, 128, 282-296. [CrossRef]

29. Jain, V.; Sachdeva, G.; Kachhwaha, S.S. Comparative performance study and advanced exergy analysis of novel vapor compression-absorption integrated refrigeration system. Energy Convers. Manag. 2018, 172, 81-97. [CrossRef]

30. Jing, Y.; Li, Z.; Chen, H.; Lu, S.; Lv, S. Exergoeconomic design criterion of solar absorption-subcooled compression hybrid cooling system based on the variable working conditions. Energy Convers. Manag. 2019, 180, 889-903. [CrossRef]

31. Colorado, D.; Rivera, W. Performance comparison between a conventional vapor compression and compression-absorption single-stage and double-stage systems used for refrigeration. Appl. Therm. Eng. 2015, 87, 273-285. [CrossRef]

32. Sahoo, P.K. Exergoeconomic analysis and optimization of a cogeneration system using evolutionary programming. Appl. Therm. Eng. 2008, 28, 1580-1588. [CrossRef]

33. Jain, V.; Surendra, G.S.; Kachhwaha, S.; Patel, B. Thermo-economic and environmental analyses based multi-objective optimization of vapor compression-absorption cascaded refrigeration system using NSGA-II technique. Energy Convers. Manag. 2016, 113, 230-242. [CrossRef]

34. Lijuan, H.; Wang, S.; Suxia, L.; Xuan, W. Numerical and experimental evaluation of the performance of a coupled vapour absorption-compression refrigeration configuration. Int. J. Refrig. 2019, 99, 429-439. [CrossRef] 
35. Jianbo, L.; Shiming, X.; Xiangqiang, K.; Kai, L.; Fulin, C. Experimental study on absorption/compression hybrid refrigeration cycle. Energy 2019, 168, 1237-1245. [CrossRef]

36. Jensen, J.K.; Markussen, W.B.; Reinholdt, L.; Elmegaard, B. On the development of high temperature ammonia-water hybrid absorption-compression heat pumps. Int. J. Refrig. 2015, 58, 79-89. [CrossRef]

37. GAMS Development Corporation. General Algebraic Modeling System (GAMS) Release 23.6.5; GAMS Development Corporation: Washington, DC, USA, 2010.

38. Drud, A. CONOPT 3 Solver Manual; ARKI Consulting and Development A/S: Bagsvaerd, Denmark, 2012.

(C) 2020 by the authors. Licensee MDPI, Basel, Switzerland. This article is an open access article distributed under the terms and conditions of the Creative Commons Attribution (CC BY) license (http://creativecommons.org/licenses/by/4.0/). 